\title{
Theoretical Foundations of Study of Cartography
}

\author{
Václav Talhofer ${ }^{\mathrm{a}}$, Š́rka Hošková-Mayerováb \\ ${ }^{a}$ University of Defence, Faculty of Military Technology, Department of Military Geography and Meteorology, Kounicova 65, 662 10 \\ Brno,Czech Republic,vaclav.talhofer@unob.cz \\ ${ }^{b}$ University of Defence, Faculty of Military Technology, Department of Mathematics and Physics, Kounicova 65, 662 10 Brno, \\ Czech Republic, sarka.mayerova@unob.cz
}

\begin{abstract}
Cartography and geoinformatics are technical-based fields which deal with modelling and visualization of landscape in the form of a map. The theoretical foundation is necessary to obtain during study of cartography and geoinformatics based mainly on mathematics. For the given subjects, mathematics is necessary for understanding of many procedures that are connected to modelling of the Earth as a celestial body, to ways of its projection into a plane, to methods and procedures of modelling of landscape and phenomena in society and visualization of these models in the form of electronic as well as classic paper maps. Not only general mathematics, but also its extension of differential geometry of curves and surfaces, ways of approximation of lines and surfaces of functional surfaces, mathematical statistics and multi-criterial analyses seem to be suitable and necessary. Underestimation of the significance of mathematical education in cartography and geoinformatics is inappropriate and lowers competence of cartographers and professionals in geographic information science and technology to solve problems.
\end{abstract}

Keywords: Cartography, Geoinformatics, Mathematics, Education, Body of Knowledge

\section{Introduction}

The study of cartography and geoinformatics at universities undergoes constant changes which are nowadays brought about especially by technical and technological development of geoinformatics and wide accessibility of positional and thematic data. Presented changes put pressure on adjustment of study plans of new topics and whole new subjects. The changes are reflected in the need of updating or creating fundamental basics of study included in the Body of Knowledge (BoK). For the field of geoinformatics, a Geographic Information Science and Technology: Body of Knowledge (GI S\&T BoK) (DiBiase, et al., 2006), which was published in 2006, is now being updated. At the same time, ICA Commission on Education and Training is preparing a similar document called the Body of Knowledge for Cartography (BoK-C) (ICA - CET, 2016).

GI S\&T BoK is focused especially on its own specialized content which is recommended while creating specific study plans. In his contribution, Fairbairn (Fairbairn, 2015) deals with an innovative approach to the education of cartographers, which should be reflected in the model of competence. Robinson points out the increasing interest in online education (Robinson, 2015) and the weaknesses in securing appropriate education.

Unfortunately, all the published materials only marginally mention areas which should create the theoretical foundations for specialized accredited study. Even though theoretical foundations are necessary for acquiring the adequate knowledge on which to build one's own specialized study. One of the basic theoretical foundation is mathematics. The following text briefly points out the necessity of teaching mathematics to cartographers and geoinformatics professionals.
Future cartographers and professionals in geographic information science and technology surely are not any special kind that needs totally different mathematics from other university students. Yet it is necessary to think which parts of mathematics are important and key for these fields, but in fact, they do not get so much space as in other fields.

For the given fields mathematics is necessary for understanding a range of procedures which relate to modelling the Earth as a celestial body, to ways of its projection into a plane, to methods and procedures of modelling landscape and processes in the society and visualization of these models in the form of electronic as well as classic paper maps. It is evident that the problematic is broad, so the following text depicts only some problems that illustrate the width of the problem in these fields and which require mathematical foundations to be correctly understood. Without these foundations, solution of special problems may not only be unsuitable, but it can lead to mistakes and faults. The aim of the text is also to contribute to the discussion about the importance of mathematics at university studies of cartography and geoinformatics.

\section{Positional basics of maps}

Wide availability of positional data from all over the world and possibilities of their integration in one computing environment is a phenomenon of today's geoinformatics and cartography world. When looking at data usage, this situation can be judged fairly positively. However, when considering data manipulation, it is necessary to identify critical places. Classical paper maps have always clearly defined positional foundations and one display. Besides that, their content is always modified to the utility properties of a given map, it is 
appropriately generalized, symbolized and explained in the map legend. A different situation occurs while using digital positional data. Digital positional data are usually geometrically located in the worldwide and national coordinate system and their user should perfectly know the properties of this system and possible ways of expressing the location of objects.

\subsection{Spatial coordinates}

Coordinate systems on referential bodies, usually ellipsoids, are used to express a position. In the past, a lot of ellipsoids that substituted the Earth. Only with the development of satellite technology, there occurred the need of definition of so-called global ellipsoids substituting the Earth as a whole. The original ellipsoids, however, are still used because they are still often a part of definitions of state coordinate systems. Ellipsoids differ in the position of their centers against the planetary system, tilting their semimajor and semiminor axis and their dimensions. Professionals in our fields, however, must be absolutely sure of the exact definition of the given system, i.e. the used referential body and its features. Relatively fundamental is the ability of the ellipsoid surface description in differential forms as well as ways of expressing of a point position in coordinates.

To express a position on or above the ellipsoid, geographic coordinates, i.e. longitude $\lambda$ and latitude $\varphi$ are used most frequently. However, also geocentric systems that relate to the given ellipsoid or sphere are very often used in which the position of the point is expressed by $\mathrm{x}$, $\mathrm{y}, \mathrm{z}$ coordinates. For successful calculations, it is necessary to know transformations between geographic and geocentric coordinates and height of the given point above the referential ellipsoid Hel. Moreover, ellipsoids are also described by radius of curvature in a certain point (meridian $\mathrm{M}$ and radius of curvature in prime vertical $\mathrm{N}$ ) so that it was possible to describe the surface of an ellipsoid in parts (Grafarend \& Krumm, 2006), (Talhofer, 2007).

While roughly till the seventies of the last century, especially geographic coordinates were used for various calculations, in the last decades, geocentric systems have been used more and more, particularly in GNSS technologies or with transformations of coordinates between individual systems. A general transformation between two systems is often solved with a standard 7parameter similarity transformation (Fig. 1. ).

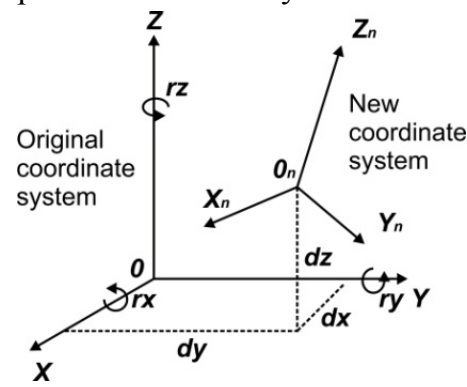

Fig. 1. 7-parametr similarity transformation

\subsection{Plane coordinates}

The resulting map image is always projected in a plane, which can be a plane of a map or a computer screen, a navigation system or a mobile phone. With respect to reality, a plane projection is always deformed in lengths, surfaces as well as angles. Already ancient Greeks dealt with a transformation of an ellipsoid or a sphere. To perform such transformation, they used primarily geometric projections, whose procedures were later also expressed in equations. Nowadays, it is based on a geometric image of transformation, but the basis is in using the solution of differential equations with defined initial conditions. According to (Talhofe, 2007) it is possible to schematically express the basis of transformation of spatial coordinates into plane ones by the following picture (Fig. 2):

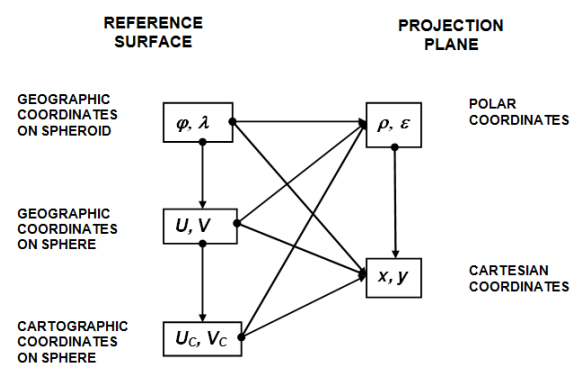

Fig. 2. Types of projections

The basis for derivation of the projecting equations is the knowledge of:

- curvatures of referential surface,

- length elements of meridians, parallels and general lines,

- and general laws of distortion of lengths, areas and angles.

With the help of differential geometry of curves and planes, it is possible to define all general lows of distortion. The projection into a plane itself is then defined as equidistant, equivalent, or conformal. Projection equations are derived based on set conditions for the given distortion which are expressed as differential equations. This equation is solved by a definite or indefinite integral with setting of the initial conditions. From the point of mathematics, knowledge of derivations and integrals, as well as a solution of nonlinear equations is necessary. Specific ways of solutions of the individual types of projections can be found e.g. in (Grafarend \& Krumm, 2006) or (Talhofer, 2007).

Together with knowledge of rules of the individual projections, it is always necessary to choose an optimal projection for the given purpose. Various methods are used to assess the suitability of projections. One of the simple and quite old methods of evaluation is so-called Tissot indicatrix, which is an image of a unit circle on an ellipsoid after its projection to a plane. The following picture shows two projections of the Earth using Tissot indicatrix

(Fig. 3). 


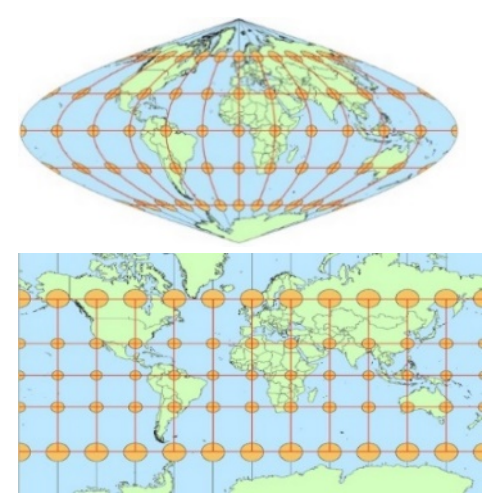

Fig. 3. Projection of the Earth, Sanson's pseudocylindrical (left) and conformal Mercator projection (right) (using data (ESRI, 2013))

It is necessary to pay attention to the choice of a suitable type of projection, especially nowadays when a large number of users use web map services (WMS) like Microsoft ${ }^{\circledR}$ Bing ${ }^{\mathrm{TM}}$ Maps, Google Maps $^{\mathrm{TM}}$, ESRI ${ }^{\circledR}$ ArcGISSM Online, etc. A lot of known projections are named after their authors who sometimes derived even more of them. Thus there can occur confusion and subsequent mistakes as pointed out by e.g. (Office of Geomatics, 2014) when using Mercator and WEB Mercator projections. The mentioned material also contains a sample of differences in the position of borders of Great Britain in various projections (Fig. 4):

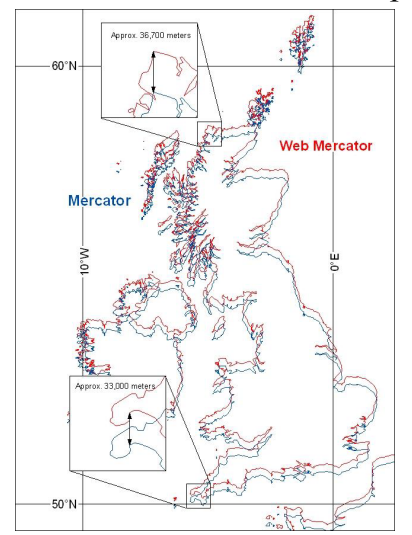

Fig. 4. Visual Example of Overlaying Ellipsoid Mercator (blue) and Web Mercator (red), graticule is WGS 84 (Office of Geomatics, 2014)

\section{Two-dimensional and three-dimensional geometry}

Positional basics create only conditions for localization of the modelled objects and phenomena in the countryside. The position of the objects themselves is then given with respect to the used data format.

For vector format, the position of objects is set as a point (point objects, points), set of successively adjacent line segments with various initial and ending point (line objects, lines) or a set of successively adjacent line segments with the same initial and ending point (planar objects, polygons). Thanks to topology, each object usually has a defined relation to its environment. A record of its properties, which are saved in a database as table of properties, are an inseparable part of the object.
From the point of spatial dimension, objects may be modelled as two-dimensional (2D), three-dimensional (3D) as well as four-dimensional (4D), where the fourth dimension is usually time. From the point of view of coordinates, it is possible to use Cartesian coordinates, as well as spherical, while it is assumed that localization is maximally accurate from the point of view of the required characteristics of the resulting model. This way, especially discrete objects are modelled.

Qualitatively different way of modelling objects and phenomena is the use of a raster format. Raster format is based on a regular grid (pixel), usually square, which completely fill the given area - raster dataset. Within a raster dataset each pixel has its unique value which may be for instance existence of an object (field, house, forest) or a value (value in the given classification scale, value of a chosen function, etc.). Raster datasets are localized in same coordinate systems as vector, i.e. in Cartesian as well as spherical. The accuracy of localization of an object or a phenomenon, however, is given by the size of the pixel, within which the accuracy does not increase.

\subsection{Work with geometry}

The record of position of the modelled objects and phenomena in the countryside is a basis to be able to answer the question "WHERE something is?" Something can be substituted by e.g. a municipality, a river, a mountain range, a castle, etc. However, the answer to question WHERE is usually not the end. Most users want to know "HOW big is it?", "HOW far or high is it?", "WHAT is in the surroundings, under or above the object?", etc. As all objects have their localization, answers to the given questions are relatively easy. It is only necessary to know methods of calculation or analysis of spatial relations in the given models.

Most answers to the mentioned and similar questions is based on calculations of distance, on an analysis of the mutual relation of two objects, on the system of work with geometry and on rules which are used in the given system.

If vector models are worked with, calculations are based on plane or spatial trigonometry. Everybody who works in this field should be sure of using basic formulas and theorems. For illustration, it is possible to use the following picture (Fig. 5) and generalized equations that solve some problems for plane polygon. The picture shows a triangle IJK, whose vertexes have known coordinates in Cartesian system, generally used in mathematics.

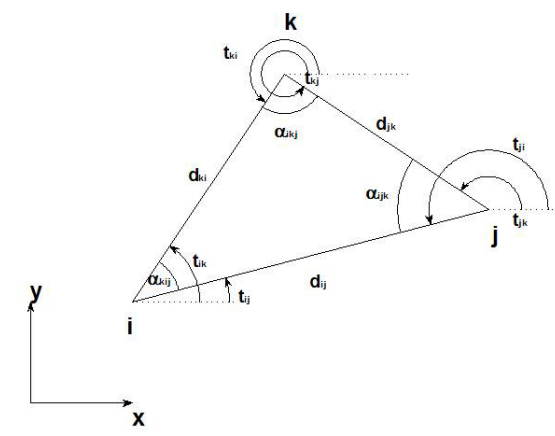


Fig. 5. Plane triangle

If the coordinates of vertexes (xi, yi) are known, it is not a problem (using the Pythagoras' theorem) to calculate their distances dij, directions tij of their sides and from them also vertex angles. This is taught even on basic schools. What is not normally taught are equations for calculations of side lengths, their directions and vertex angles of polygons with the addition of calculations of circumference, surfaces and centroids. However, in geoinformatics, these problems are very frequent because firstly, objects are usually of an irregular shape (footprint), secondly, it is often necessary to know their above-mentioned spatial characteristics.

From the point of view of mathematics, the stated calculations are correct, but from the point of view of geoinformatics and cartography the situation might get rather complicated (and it very often does), because of historical and practical reasons classic Cartesian system is not often used, but the position of coordinate axes, their orientation and orientation of directions (here very often called bearing and marked as $\sigma$ ) may vary in different coordinate systems. The following picture (Fig. 6) shows the real state in the Czech Republic. As all systems are used in practice, it is necessary to know exactly their characteristics and to be able to deal with modification of the above-mentioned formulas for a specific coordinate system. Also, confusion of coordinates in different systems cannot occur, as it could have fatal consequences.

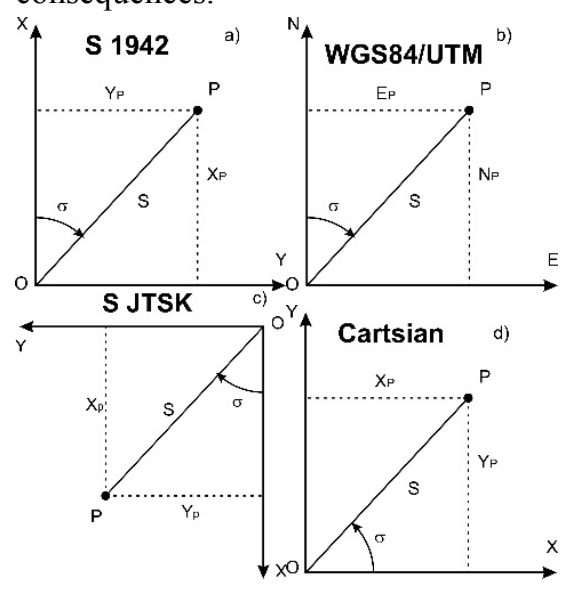

Fig. 6. Systems of coordinates used in the Czech Republic: a) $\mathrm{S}$ 1942 (Pulkovo), Gaussian projection; b) WGS84, UTM projection; c) S-JTSK, Krovak projection, used mainly for cadaster and civilian state mapping; d) Cartesian coordinate system.

\subsection{Accuracy of geometric problems}

Objects and phenomena in the countryside are modelled in the environment of geoinformatics systems only with defined, required or really achievable accuracy. For instance, a footprint of a building can be measured with the accuracy of several centimeters; borderline of forest can be set with the accuracy of meters, but borders between two soil types with the accuracy of several hundred meters. Similarly, also accuracies of setting or deriving thematic features of objects are classified. That is why while solving all problems in GIS environment, it is necessary to take into account characteristics of accuracy and a way how the accuracy in position as well as in thematic features affects the results of various analyses, research, etc. Mathematical basics are once again necessary for understanding of the whole problem.

For evaluation of the accuracy of localization of discrete objects (geodetic points, buildings, poles, etc.) it is possible to use calculus of probability and function of normal distribution. It is possible to set e.g. probable position of a geodetic point with a defined level of reliability, usually $\alpha=0.05$. Another used characteristic is mean positioning error, or standard deviation.

Most objects and phenomena in the countryside, however, are not utterly discrete, but they are connected to its surroundings. A house stands on a parcel; it means that where the footprint of the building ends, the object of parcel begins. A forest and a meadow also have a common border. While working with vagueness of such borders, calculus of probability is not an optimal tool, because it is possible to work only with one type of objects. Using fuzzy sets here seems to be very useful. Fuzzy sets enable to mathematically solve a change of membership to the given object given by vagueness of borders of the neighboring objects (Zadeh, 1965), (Talhofer, Hoskova-Mayerova, \& Hofmann, 2012). Principles of using fuzzy sets in geoinformatics are dealt with e.g. by (Kainz, 2007) and they are also applied in program systems GIS, e.g. (ESRI, 2013). According to (Kainz, 2007), membership to given objects may be modelled by various types of functions.

Using fuzzy sets for a calculation of membership of terrain sections to roads is shown in the picture (Fig. 7). In GIS database certain types of roads (field tracks and gravel tracks) are defined only as a point set in the axis of the road. As data about width of roads are missing in thematic features, but in reality this width is usually 5 meters, linear membership function to roads in the surroundings of the axis of roads of 5 meters to both sides was chosen here (Hofmann, Hoskova-Mayerova, \& Talhofer, 2013).

The presented simple example is only illustrative. For an effective use of fuzzy sets in positional analyses it is necessary to draw on the theory of fuzzy sets. For example, choose suitable shapes of membership functions in terms of the geographical nature of objects and phenomena and appropriate limit in which this membership is computed.

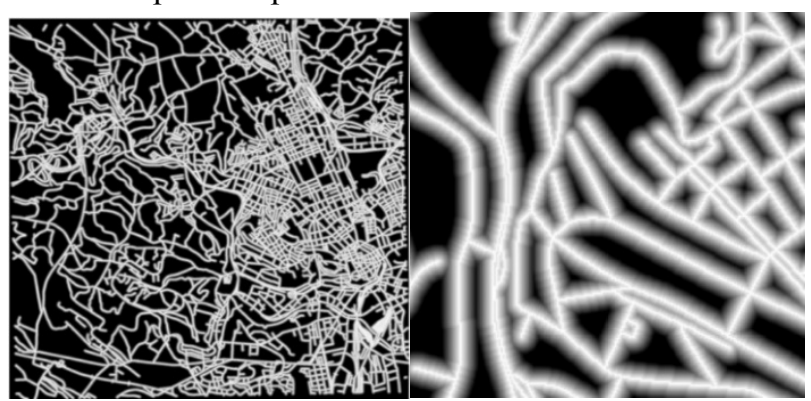

Fig. 7. Fuzzyfied roads; on the left all roads in the given area, detail on the right 


\section{Cartographic visualization of objects}

The whole problem of cartographic visualization is described in complex in a range of sources, let us mention e.g. (MacEachren, 2004), (Slocum, et al., 2005), (Kraak \& Ormeling, 2010), (Lauermann, 1974), (Rystedt, et al., 2014), (Voženílek, et al., 2011) or (Kovarik \& Marsa, 2014). The following text thus gives only chosen examples of methods of cartographic visualization which relate to mathematics and therefore are illustrative from this point of view.

Each map symbol expresses the position and geometry of an object, its qualitative and quantitative features. According to (Bertin, 1967), it is possible to describe every map symbol with graphic variables, which are position, shape, size, value, pattern, colour, and orientation. These symbol variables fully comply with visualization of objects for classic maps and virtual maps that are not of a dynamic character.

\subsection{Cartographic generalization}

It is obvious that for quality and readable visualization it is necessary to modify a lot of presented information. It is necessary to choose objects that shall be visualized, choose and potentially modify their thematic features according to which they will be visualized, and the whole visualized content to put in harmony so that there were no overlays of map symbols (Voženílek, at al, 2011). This complete procedure is called cartographic generalization. Cartographic generalization is a traditional field of cartography which was developed by many authors, e.g. (Srnka, 1968), (Töpfer, 1974), (Lauermann, 1974). Contemporary approach to cartographic generalizations comes from classic work from the times when maps were created predominantly manually, but it is developed especially under the influence of work with digital data and web mapping services (Neun, et al., 2007), (Neun, 2007), (van Altena, et al., 2013). Most of program systems for work with digital data contain sets of tools for cartographic generalizations, e.g. System ArcGIS by ESRI (ESRI, 2013).

Tools of cartographic generalization are based on mathematical principles, above all, on applications of analytic geometry, functions of approximation and on tests of mutual position of points, lines or line segments and surfaces. One of the simple tools is e.g. modification of geometry of line objects which may be solved by the reduction of their definition point set. Descriptions of many tools may be found in materials (Bayer, 2013), where the tools are divided into mechanical and global.

Basic mechanical tools are length or angle tests, during which two or three consecutive points are worked with, and with beforehand given minimal (testing) value. More complex algorithms based on gradual recursive approximation of the whole line are called global algorithms, Douglas-Paucker algorithm is the most frequently used. Its description and explanation can be found in (Bayer, 2013), concrete implementation then in tools of ArcGIS (ESRI, 2013).
After reduction of point sets, sets usually approximate to smooth curves which correspond to the reality in the countryside. Smoothing algorithms are derived from mathematical principles and their inspiration cartographers often adopted from CAD systems. Basically there are three types of algorithms used: smoothing by averaging of points, smoothing by filtering, smoothing using approximation curves.

As smoothing concerns visualization of objects in the countryside, it is necessary to know the fundaments and functionality of algorithms so that inappropriate reduction of significant shape characteristics of objects was prevented, as well as adding of shapes that the objects do not possess (especially with approximation of polynomials of higher degrees). It is obvious that e.g. a river on the middle course which is marked with frequent meanders has absolutely different geometric character than a highway or railway. That is why it is necessary to choose smoothing algorithms with respect to geographic nature of the modelled object.

Modification of geometry is done progressively with individual thematic layers (bodies of water, roads, builtup area, etc.). After these modifications it is necessary to perform so-called cartographic harmonization whose purpose is to search for all places where the projected objects after merging of all layers into one image cross, overlay, are unfinished, etc. If this was the case, the resulting cartographic visualization would be unreadable and would not correspond to the reality. To detect the mentioned facts (conflicts), it is possible to use spatial overlays with a calculation of conflict places. The theoretical basis for conflict detection have to be again found in mathematics and analytical geometry.

\section{Analysis of thematic data and information and their visualization}

In the previous paragraphs, there are examples especially of work with geometry of objects. The power of geoinformatics, however, lies also in keeping thematic features of objects. Basically, it is possible to connect unlimited number of thematic information relating to the object or a group of objects.

Thematic information, however, is not only saved but it is often analysed, we look for its connections, relations and dependencies. An analysis of spatial information and their thematic features is again a very wide field which rapidly develops either methodically as well as mathematically. Mathematical models of spatial analyses may be found in many sources, e.g. (Cressie, 1993), (Rybansky \& Vala, 2010), (Wilson \& Gallant, 2000) and others. A lot of principles come from theorems of mathematical analysis, mathematical statistics, work with bulk data, etc. With the help of spatial analysis, for instance, suitable locations for constructions are looked for, movement of people and goods is watched, and trends of development of objects and especially phenomena are determined (Svatonova \& Rybansky, 2014). 
Mathematics and mathematical statistics are absolutely essential prerequisites for quality processing of data and information. Without knowledge of their theoretical principles and practical applications it is not possible to complete a quality spatial analysis. Nevertheless, there are many pitfalls that are necessary to take into account.

Mathematical statistics often works with statistical files which have a definable division. Thematic data in geoinformatics, however, are a model of reality in the countryside which is not possible to easily describe in mathematic terms. A multi-criterial analysis is quite frequently used procedure (Rybansky \& Vala, 2010).

Complex program systems for GIS, e.g. often mentioned ArcGIS, contain strong tools for solution of spatial analyses including the mentioned example (ESRI, 2013). An analyst, who is able to use tools of such program systems, is able to solve such and similar analyses quite easily and to pass the result to the ordering party who may use the result e.g. to make a decision where to invest money to support lagging regions which are becoming depopulated. However, this is very often the pitfall of these solutions. Without understanding geographical relations and geostatistical principles, it is possible even with correct data to "produce" a misleading analysis which nobody will examine any more but they will only adopt its results. If the worker creating spatial analyses has not acquired sufficient fundamentals of general statistics, extended by geo-statistics, or for some reason is too inactive to merge into the problem, he/she may create an absolutely misleading analysis even from quality data.

\section{Conclusion}

As was mentioned in the introduction of this text, it was not ambition to define absolutely all requirements on knowledge of mathematics for students and graduates of cartography and geoinformatics. Nevertheless, the article indicated the width of the problem in the given fields for which basics in mathematics and statistics are necessary. Just like at all universities oriented to technical and natural fields, it is obvious that without solid fundamentals in mathematics it is not possible to successfully master professional problematics. Of course, the required level will depend on the level of study, it will be different in bachelor study, other in master study and totally different in $\mathrm{PhD}$ programs, from the point of studied fields of mathematics, as well as their depth.

While creating the BoK - C draft, it would be appropriate not to stop with defining the competence of the study graduates in terms of their own expertise, but it would be useful to implement also the competence of general knowledge and skills, including mathematics.

From the point of view of fields of mathematics, knowledge and competences of general university mathematics are needed, such as arithmetic, algebra, matrix calculation, goniometric and inverse goniometric functions, differential and integral calculation, etc.

As was to point out, extension of mathematics by plane and spherical trigonometry and its solution using especially analytical procedures in various types of coordinate systems seems to be right. Furthermore, usage of differential geometry of curves and surfaces for the solution of procedures of transformation of spatial bodies into a plane is also a good idea. Knowledge of theory and analytical solutions of affinitive and projective transformations mainly for work with visual data from aerial and land cameras and data of remote sensing is also very useful. For work with geographic data and for their analyses, it is useful to know interpolation methods in a plane, as well as in space, and ways of approximation of lines and surfaces by functional surfaces. It seems essential to study the methods and procedures of mathematical statistics and calculus of probability.

Mathematics is fundamental for understanding of many expert problems that may be solved by program tools, but without the knowledge of theory the researcher may make serious mistakes. Mathematics pushes to precision of the solution and precision of its description in documentation of the procedure.

Mathematics itself is a complex subject, it has its theory, its rules and its procedures. It often happens that for a non-mathematician pure mathematics seems incomprehensible which might lead them to turn away from it. To prevent this from happening, also mathematicians must understand requirements of technicians. For technicians, mathematics must be comprehensible and applicable. A mathematician who teaches a technical subject should - at least in basics understand this subject and indicate what is important for the subject and what theoretical and application ways can be used to solve problems. Attitude of some mathematicians is actually to the detriment of the cause as they are not interested in applications and do not let the users find applications themselves. In my opinion, this attitude is inappropriate as mathematics must help us solve our problems. A suitable procedure seems to be to include mathematicians in a team of researchers who try to move the theory and practice of cartography and geoinformatics forward.

\section{Acknowledgements}

The work presented in this paper was supported within the project for "Development of the methods of evaluation of environment in relation to defense and protection of the Czech Republic territory" (Project code NATURENVIR) and "Development of the methods for increasing mobility of military vehicles" (Project code MOBAUT) supported by the Ministry of Defence the Czech Republic.

\section{References}

Bayer, T. (2013). Výukové materiály pro studium oboru aplikované geoinformatiky a kartografie. Praha: Katedra aplikované geoinformatiky a kartografie, Př́rodovědecká fakulta, Univerzita Karlova. In Czech.

Bertin, J. (1967). Sémiologie graphique : Les diagrammes - Les Réseaux - Les Cartes. Paris: Mounton.

Cressie, N. A. (1993). Statistics for Spatial Data. New York, USA: John Wiley \& Sons, INC. 
DiBiase, D., DeMers, M., Luck, A. T., Johnson, A., Plewe, B., Kemp, K., \& Wentz, E. (2006). Geographic Information Science and Technology: Body of Knowledge 2006. 127. Abington: University Consortium for Geographic Information Science.

ESRI. (2013). User documentation. Copyright (C) 19952013 Esri.

Fairbairn, D. (2015). What is to be done? Syllabus content for cartographic education. In M. d. all (Ed.), 27th International Cartographic Conference (p. 9). Rio de Janeiro: Curitiba/PR, Brazil . Retrieved 09 15, 2016, from

http://icaci.org/files/documents/ICC_proceedings/ICC2 015/papers/22/695.html

Grafarend, E. W., \& Krumm, F. W. (2006). Map Projections: Cartographic Information System. Heidelberg, Germany: Springer-Verlag.

Hofmann, A., Hoskova-Mayerova, S., \& Talhofer, V. (2013). Usage of fuzzy spatial theory for modelling of terrain passability. Advances in Fuzzy Systems, 2013, p. 13.

ICA - CET. (2016). Internatinal Cartographic Association - Commission on Education and Training. Retrieved 09 16, 2016, from ICA: http://education.icaci.org/

Kainz, W. (2007). Fuzzy Logic and GIS. Vienna, Austria: University of Vienna.

Kovarik, V., \& Marsa, J. (2014). Specifics of thematic map production within geospatial support at a politicostrategic level. Geographia Technica, 9(1), pp. 52-65.

Kraak, M.-J., \& Ormeling, F. (2010). Cartography: Visualization of Geospatial Data (Third ed.). Harlow, Essex, England: Pearson Education Limited.

Lauermann, L. (1974). Technická kartografie I. Brno: Vojenská akademie Antonína Zápotockého. In Czech

MacEachren, A. M. (2004). How Maps Works: Representation, Visualization and Design. New York, USA: The Guilford Press.

Neun, M. (2007). Data Enrichment for Adaptive Map Generalization Using Web Services (PhD Thesis ed.). Zurich: Universitat Zurich.

Neun, M., Burghardt, D., \& Weibel, R. (2007). Automated Processing for Map Generalization with Modular Operator Services. Retrieved 10 12, 2012, from University of Zurich, Department of Geography: http://www.geo.unizh.ch/ neun/publications/webgen/ge oinformatica-submitted.pdf

Office of Geomatics. (2014). Implementation Practice Web Mercator Map Projection (Version 1.0.0 ed.). Washington D.C., USA: National GeospatialIntelligence Agency (NGA). Retrieved 02 09, 2015, from http://earthinfo.nga.mil/GandG/wgs84/web_mercator/\%28U\%29\% 20NGA_SIG_0011_1.0.0_WEBMERC.pdf

Robinson, A. C. (2015). Challenges and Opportunities for Massive Open Online Cartographic Education. In M. d. all. (Ed.), 27th International Cartographic Conference (p. 2). Rio de Janeiro : Curitiba/PR, Brazil 2015. Retrieved $09 \quad 15, \quad 2016, \quad$ from http://www.icc2015.org/abstract,437.html

Rybansky, M., \& Vala, M. (2010). Relief impact on transport. ICMT'09: International Conference on Military Technologies (pp. 551-559). Brno: University of Defence.

Rystedt, B., Ormeling, F., Vozenilek, V., Lapaine, M., Huét, M., Zentai, L., . . . Fairbairn, D. (2014). The World of Maps. ICA: International Cartographic Association. Retrieved 2014, from http://mapyear.org/the-world-of-maps-book/

Slocum, T., McMaster, R., Kessler, F., \& Howard, H. (2005). Thematic Cartography and Geographic Visualization (2 ed.). Upper Saddle River, NJ 07458: Pearson Education, Inc.

Srnka, E. (1968). Analytické řešení generalizace v kartografii (Analitical solution in the cartographic generalization, in Czech) (Habilitation theses ed.). Brno: Military Academy in Brno.

Svatonova, H., \& Rybansky, M. (2014). Visualization of landscape changes and threatening environmental processes using a digital landscape model. IOP Conf. Ser.: Earth Environ. Sci. 18. 18, pp. 12-18. IOP science.

Talhofer, V. (2007). Základy matematické kartografie. Brno: Univerzita obrany. In Czech.

Talhofer, V., Hoskova-Mayerova, S., \& Hofmann, A. (2012). Improvement of digital geographic data quality. International Journal of Production Research, 50(17), pp. 4846-4859.

Töpfer, F. (1974). Kartographische Generalisierung. Leipzig: VEB Hermann Haack.

van Altena, V., Post, M., Nijhuis, R., \& Stoter, J. (2013). Generalisation of $1: 50 \mathrm{k}$ roads centrelines from $1: 10 \mathrm{k}$ road polygons in an automated workflow. 16th ICA Workshop on Generalisation and Map Production. Dresden.

Voženílek, V., Kaňok, J., Bláha, J. D., Dobešová, Z., Hudeček, T., Kozáková, M., \& Němcová, Z. (2011). Metody tematické kartografie, vizualizace prostorových jevů. Olomouc, Česká republika: Univerzita Palackého. In Czech

Wilson, J. P., \& Gallant, J. C. (2000). Terrain Analysis: Principles and Applications. New York: John Wiley \& Sons. Inc.

Zadeh, I. (1965). Fuzy Sets. Information and Control, 8, pp. $338-353$. 